\title{
Timing of emergency IUD fitting
}

We wish to thank Dr Davies ${ }^{1}$ for raising an issue we were not able to address in our original letter ${ }^{2}$ due to space limitations. The issue with emergency contraception intrauterine devices (EC IUDs) is slightly different. An EC IUD has to be fitted prior to implantation. This is a process that starts no sooner than 6 days after fertilisation, and fertilisation cannot happen prior to sexual intercourse. So, if all the risks are within 120 hours the IUD can always be considered regardless of where the woman may be in her cycle.

Any risks more than 3 weeks ago warrant a pregnancy test, which will give a clear result.

For risks between 3 weeks and 120 hours the date of the last normal 
menstrual period (LMP) and cycle length can be used but a conservative approach is advised. The questions to ask are: "What is the earliest date that your last period could have started?" and "What is the shortest length of time from the start of one period to the start of the next that you experience when not using hormonal contraception?" This will enable calculation of the earliest possible ovulation date, and by adding 5 days the latest date before which implantation could not have started. This may lead to some women not being able to access an EC IUD though they have not yet ovulated but will not risk insertion after implantation.

Prior use of oral EC may delay ovulation but will not bring it forward so should not affect the calculation of dates for insertion of an EC IUD.

The concern with not offering ulipristal acetate when a woman appears to be in the luteal phase, from LMP and cycle length calculation, is that quite a few women will not yet have ovulated and only offering the least effective method when all risks are within 120 hours goes against guidelines ${ }^{3}$ and denies the woman a better chance of reducing the risk of an unplanned pregnancy.

Anne Webb, FFSRH

Consultant in Sexual and Reproductive Health, Liverpool Community Health, Liverpool, UK; anne.webb@liverpoolch.nhs.uk

Pauline McGough, MRCOG, MFSRH

Consultant in Sexual and Reproductive Health, Clinical Director, Sandyford, Glasgow, UK; paulinemcgough@nhs.net

Louise Melvin, MRCOG, MFSRH

Director, FSRH Clinical Effectiveness Unit, Sandyford, Glasgow, UK; louise.melvin@nhs.net

Competing interests None.

J Fam Plan Reprod Health Care 2013;39:61-62. doi:10.1136/jpprhc-2012-100535

\section{REFERENCES}

1 Davies G. Ulipristal acetate emergency contraception. J Fam Plann Reprod Health Care 2013;39:61.

2 Webb A, McGough P, Melvin L. Pitfalls of adapting emergency contraception CEU guidance. J Fam Plann Reprod Health Care 2012;38:270.

3 Faculty of Sexual and Reproductive Healthcare. Emergency Contraception. 2011. http://www.fsrh.org/pdfs/CEUguidance EmergencyContraception11.pdf [accessed 16 October 2012]. 